Florida International University FIU Digital Commons

FCE LTER Journal Articles

FCE LTER

2009

\title{
Roseate spoonbill reproduction as an indicator for restoration of the Everglades and the Everglades estuaries
}

Jerome J. Lorenz

Audubon of Florida, Tavernier Science Center

Brynne Langan-Mulrooney

Audubon of Florida, Tavernier Science Center

Peter E. Frezza

Audubon of Florida, Tavernier Science Center

Rebecca G. Harvey

University of Florida, Ft. Lauderdale Research and Education Center

Frank J. Mazzotti

University of Florida, Ft. Lauderdale Research and Education Center

Follow this and additional works at: https://digitalcommons.fiu.edu/fce_lter_journal_articles

Part of the Life Sciences Commons

\section{Recommended Citation}

Lorenz, J.J., B. Langan-Mulrooney, P. Frezza, R.G. Harvey, F.J. Mazzotti. 2009. Roseate spoonbill reproduction as an indicator for restoration of the Everglades and the Everglades estuaries. Ecological Indicators 9(6): S96-S107.

This material is based upon work supported by the National Science Foundation through the Florida Coastal Everglades Long-Term Ecological Research program under Cooperative Agreements \#DBI-0620409 and \#DEB-9910514. Any opinions, findings, conclusions, or recommendations expressed in the material are those of the author(s) and do not necessarily reflect the views of the National Science Foundation. This work is brought to you for free and open access by the FCE LTER at FIU Digital Commons. It has been accepted for inclusion in FCE LTER Journal Articles by an authorized administrator of FIU Digital Commons. For more information, please contact dcc@fiu.edu, jkrefft@fiu.edu. 
Elsevier Editorial System(tm) for Ecological Indicators

Manuscript Draft

Manuscript Number:

Title: Roseate Spoonbills as an Indicator for Restoration of the Everglades and Florida Bay

Article Type: Indicators for Restoration

Section/Category:

Keywords: ecological indicators, Everglades restoration, Roseate Spoonbill, Wading Birds, restoration assessment

Corresponding Author: Dr. Jerome J Lorenz, Ph.D.

Corresponding Author's Institution: Audubon of Florida

First Author: Jerome J Lorenz, Ph.D.

Order of Authors: Jerome J Lorenz, Ph.D.; Brynne Langan-Mulrooney, B.S.; Peter E Frezza, MS; Frank J Mazzotti, Ph.D.

Manuscript Region of Origin:

Abstract: Ecological monitoring is a key part of adaptive management and successful restoration. Not everything within an ecosystem can be monitored so it is important to select indicators that are representative of the system, integrate system responses, show clear responses to system change, can be effectively and efficiently monitored, and are easily communicated. Roseate Spoonbills are one of the indicators that meet these criteria within the Everglades ecosystem. Monitoring of Roseate Spoonbills in Florida Bay over the past 70 years has shown that this species responds to changes in hydrology and corresponding changes in prey abundance and availability. This indicator uses nesting location, nest numbers and nesting success in response to food abundance and availability. In turn, prey abundance is a function of hydrological conditions including depth, and salinity. These relationships have been well documented such that spoonbills responses can be directly related to changes in hydrology and salinity. The spoonbill indicator uses performance measures that have been shown to be both effective and efficient 
in tracking trends. They are: nesting success, nest number, locations of nests, and prey fish community composition. Targets for these performance measures we established based on previous findings. The performance measures are then reported as suitability indices identified as stoplight colors with green indicating that targets have been met, yellow indicating that conditions are below the target but within a suitable range of it and red indicating the measure is performing poorly in relation to the target. 


\section{Florida Bay}

4 Jerome J. Lorenz*, Audubon of Florida, Tavernier Science Center, 115 Indian

5 Mound Trail, Tavernier FL 33070. Ph: 305-852-5318, Fax: 305-852-8012,

6 jlorenz@audubon.org

8 Brynne Langan-Mulrooney, Audubon of Florida, Tavernier Science Center, 115

9 Indian Mound Trail, Tavernier FL 33070. Ph: 305-852-5318, Fax: 305-852-8012,

10 blangan@audubon.org

11

12 Peter E. Frezza, Audubon of Florida, Tavernier Science Center, 115 Indian

13 Mound Trail, Tavernier FL 33070. Ph: 305-852-5318, Fax: 305-852-8012,

14 pfrezza@audubon.org

15

16 Frank J. Mazzotti, University of Florida, Ft. Lauderdale Research and Education

17 Center, 3205 College Avenue, Davie Florida 33314. fjmaAufl.edu

$23 *$ Corresponding author 


\section{Abstract}

25 Ecological monitoring is a key part of adaptive management and successful

26 restoration. Not everything within an ecosystem can be monitored so it is important to

27 select indicators that are representative of the system, integrate system responses, show

28 clear responses to system change, can be effectively and efficiently monitored, and are

29 easily communicated. Roseate Spoonbills are one of the indicators that meet these

30 criteria within the Everglades ecosystem. Monitoring of Roseate Spoonbills in Florida

31 Bay over the past 70 years has shown that this species responds to changes in hydrology

32 and corresponding changes in prey abundance and availability. This indicator uses

33 nesting location, nest numbers and nesting success in response to food abundance and

34 availability. In turn, prey abundance is a function of hydrological conditions including

35 depth, and salinity. These relationships have been well documented such that spoonbills

36 responses can be directly related to changes in hydrology and salinity. The spoonbill

37 indicator uses performance measures that have been shown to be both effective and

38 efficient in tracking trends. They are: nesting success, nest number, locations of nests,

39 and prey fish community composition. Targets for these performance measures we

40 established based on previous findings. The performance measures are then reported as

41 suitability indices identified as stoplight colors with green indicating that targets have

42 been met, yellow indicating that conditions are below the target but within a suitable

43 range of it and red indicating the measure is performing poorly in relation to the target.

45 Key words: ecological indicators, Everglades restoration, Roseate Spoonbill,

46 Wading Birds, restoration assessment 


\section{Introduction and Background}

Ecological monitoring is a key part of adaptive management (Williams et al.,

50 2007, Lovett et al., 2007) and successful restoration. Not everything within an ecosystem

51 can be monitored so it is important to select indicators that are representative of the

52 system, integrate system responses, show clear responses to system change, can be

53 effectively and efficiently monitored, and are easily communicated (Doren, 2006, Doren

54 et al., intro chapter, Schiller et al., 2001).

Roseate Spoonbills are one of the indicators that meet these criteria within the

57 Everglades ecosystem. Restoration of hydrology is a major part of the Comprehensive

58 Everglades Restoration Plan (CERP, U.S. Army Corps of Engineers, 1999), and

59 indicators used for tracking progress of Everglades restoration should have clear

60 relationships to hydrologic conditions (Doren et al., intro. chapter, U. S. Army Corps of

61 Engineers, 2004).

62

63 Monitoring of Roseate Spoonbills (Platalea ajaia) in Florida Bay over the past 70

64 years has shown that this species responds to changes in hydrology and corresponding

65 changes in prey abundance and availability (Powell et al., 1989, Lorenz et al., 2002).

66 This indicator uses nesting location, nest numbers and nesting success in response to food

67 abundance and availability. In turn, prey abundance is a function of hydrological

68 conditions including depth, and salinity (Lorenz and Serafy, 2006). These relationships 
69 have been well documented such that spoonbills responses can be directly related to

70 changes in hydrology and salinity (Lorenz and Serafy, 2006).

72 Spoonbill nesting success is dependent on suitable environmental conditions.

73 Correlations between biological responses and environmental conditions contribute to an

74 understanding of the species' status and trends over time (Lorenz, 2000, Lorenz and

75 Serafy, 2006). The positive or negative trends of this indicator relative to hydrological

76 changes (Lorenz, 2000, Lorenz et al., 2002, Bartell et al., 2005) permit an assessment of

77 positive or negative trends in restoration. Restoration success or failure would be

78 evaluated by comparing recent and future trends and status of spoonbills with historical

79 population data and model predictions, as stated in the CERP hypotheses related to the

80 food web (CERP Monitoring and Assessment Plan section 3.1.2.4; U. S. Army Corps of

81 Engineers, 2004).

82

83 The spoonbill indicator uses performance measures that have been shown to be

84 both effective and efficient in tracking trends. They include: nesting success, nest

85 number, locations of nests, and prey fish community composition. These parameters

86 have been correlated with hydrologic conditions including water depth, hydroperiod,

87 timing, spatial extent and salinity, which are influenced by water management practices.

89 Roseate Spoonbills are one of several charismatic megafauna found in the

90 Everglades. They are both umbrella and flagship species to which the public can relate.

91 In addition, the parameters used to track trends are easy to understand: How have the 
92 number of spoonbills changed through time? Are they as productive as they were

93 historically? Are the animals in the places where they should be? Are their prey as

94 abundant as under natural conditions?

95

96

1.1. Indicator History

97 There is a seventy year intermittent database of spoonbill nesting activity in

98 Florida Bay (Figure 1). Lorenz et al., (2002) demonstrated that nesting patterns are

99 highly dependant on hydrologic conditions on the foraging ground most proximal to the

100 nesting colonies (Figure 2). Spoonbills primarily feed on wetland fishes (Dumas, 2000)

101 and time their nesting with low water levels which result in the prey base fishes

102 becoming highly concentrated into the remaining wetted areas (Loftus and Kushlan,

103 1987, DeAngelis et al., 1997, Lorenz, 2000). Studies suggest that tactile feeding wading

104 birds, such as the Roseate Spoonbill, are particularly dependent on high prey density in

105 order to successfully forage, probably more so than the visually oriented avian predators

106 (Kahl, 1964, Frederick and Spalding, 1994, Gawlik, 2002). Tactile feeders are more

107 efficient when prey density is very high and visual predators are more efficient at lower

108 prey densities (Kahl, 1965). Gawlik (2002) experimentally demonstrated that two

109 species of tactile feeders (wood storks and white ibis) abandoned foraging sites while

110 prey was still abundant enough to attract visually oriented wading birds in high numbers.

111 Although no spoonbills visited the study site, Gawlik's (2002) experimental approach

112 lends empirical evidence to the idea that tactile feeders are more sensitive to prey

113 availability. Because tactile foraging birds in general and roseate spoonbill in particular

114 are more dependant on high prey concentration than other wading bird species (Kahl, 
115 1964, Gawlik, 2002), they are more sensitive to changes in environmental conditions that

116 determine fish concentrations, specifically water levels (Gawlik, 2002). The requirement

117 for highly concentrated prey is exacerbated during nesting cycles when the high-energy

118 demands of their offspring require a consistently available high density of prey items

119 (Kahl, 1964, Lorenz, 2000, Dumas, 2000).

120

121 Beginning with the completion of a series of canals and water-control structures

122 known as the South Dade Conveyance System (SDCS) in the early 1980's, water

123 deliveries to Taylor Slough and northeastern Florida Bay (Figure 2) changed dramatically

124 (Light and Dineen, 1994, McIvor et al., 1994, Lorenz, 2000). This canal system is

125 immediately adjacent to Taylor Slough and just upstream from where the majority of

126 spoonbills nested in Florida Bay at the time (Figure 2; Powell et al., 1989) and heavily

127 impacted the coastal wetlands that were the primary feeding grounds for the spoonbill

128 nesting population (Bjork and Powell, 1994). In 1979, 1,250 Roseate Spoonbill nests

129 were located in Florida Bay, with more than half the nests located in the northeastern bay

130 (Figure 1, Powell et al., 1989, Lorenz et al., 2002). Today, the number of nests is less

131 than a third of that in 1979 and distribution of nesting by roseate spoonbills has shifted

132 from northeastern Florida Bay to the northwestern region (Figure 2, Lorenz et al., 2002).

133 The shift is attributed to the lack of nest production following the completion of the

134 SDCS: Lorenz et al., (2002) calculated that prior to the SDCS northeastern Florida Bay

135 produced an average of 1.38 chicks per nest attempt but dropped to 0.67 chicks per nest

136 following its' completion. Lorenz (2000) demonstrated that this decline was the result of 
137 the SDCS causing changes in hydrology and salinity that affected the production (Figure

138 3) and availability of the spoonbill prey base.

140 In addition to a large nesting population in Florida Bay, spoonbills "nested in the

141 thousands" along the southwest coast south of Cape Romano (Scott, 1889). Restoration

142 of more historic hydrological conditions should promote greater prey abundance and

143 availability in both Florida Bay and the southwestern estuaries of the Everglades, leading

144 to an increase in the number of years spoonbills can successfully nest, defined as the

145 survival of offspring to fledging. Therefore, roseate spoonbills are good indicators for

146 evaluating the CERP's effectiveness at restoring estuarine conditions (Lorenz et al., 147 2002).

149 The major anthropogenic perturbations to spoonbill foraging grounds have been

150 the filling of wetlands for urban development in the upper Florida Keys and the alteration

151 of wetland type and function along the northeast coast of Florida Bay by water

152 management practices (Lorenz et al., 2002). A striking implication of these findings is

153 that current water management practices in the southern Everglades have resulted in the

154 ecological degradation of the coastal wetlands in northeastern Florida Bay.

\section{$156 \quad 1.2$ CERP Hypotheses for Spoonbills}

158 A system-wide Monitoring and Assessment Plan (MAP) has been developed that 159 describes the monitoring necessary to track ecological responses to Everglades 
160 restoration (U.S. Army Corps of Engineers, 2004). Included in that plan are descriptions

161 of selected indicators, how those indicators are linked to key aspects of restoration

162 (hypotheses), and performance measures (monitoring parameters). MAP hypotheses for

163 Roseate Spoonbills are:

164

- $\quad$ Spoonbill's should experience successful nesting (defined as an average production of $>1$ chick/nest) in 7 of 10 years and average 1.5 chicks/nest overall (initially using a five year running average for nest production and a ten year running average successful years).

- $\quad$ Restore nest numbers to pre-SDCS levels of 1250 nests with at least half in the northeastern region (as defined by Lorenz et al., 2002) of Florida coast of Florida in the estuarine areas of Shark River and Lostman's sloughs (Figure 2).

$178 \quad$ 1.3. Areas of the Everglades this Indicator Covers Spoonbills are found throughout the Everglades landscape, however, the species

181 is predominantly an indicator for the Florida Bay estuary (Figure 2) and cover the Greater 182 Everglades and Southern Estuaries region. Spoonbills are included as attributes in the 
183 Total System, Everglades Mangrove Estuaries, and Florida Bay conceptual ecological

184 models. A monitoring and assessment plan has been developed for spoonbills nesting in

185 Florida Bay. We perform a complete nest count of the entire bay, monitor nesting success

186 at focal colonies in five regions of Florida Bay and perform quantitative assessments of

187 the mangrove fish community which makes up the bulk of the spoonbill's diet while

188 nesting in Florida Bay.

\section{1.4. Significance of the Indicator to Everglades Restoration}

191 1.4.1. The indicator is relevant to the Everglades ecosystem and responds to

192 variability at a scale that makes it applicable to a large or portion of the ecosystem.

194 Spoonbills were abundant in Florida Bay and throughout the Southern Estuaries 195 region prior to Everglades drainage activities and have responded negatively to water 196 management activities. They are top predators that share a common prey base (small 197 demersal fishes) and foraging habitat with myriad other species. Spoonbills feed by 198 tactolocation rather than visual hunting; this makes them more sensitive to perturbations 199 than the other species dependant on the same resource (i.e., they are an early warning 200 indicator). Spoonbill nesting productivity is directly linked to hydrologic conditions 201 within the Southern Estuaries and nest production is linked to hydrology through the 202 impact of water management on primary producers (e.g. periphyton, submerged aquatic 203 vegetation) and lower trophic level consumers (i.e., prey base fishes). 
207 Research on Roseate Spoonbills has been conducted for over 70 years, providing a 208 remarkable long-term data base. Currently, there are funded cooperative research and 209 monitoring programs with U.S. Fish and Wildlife Service, Everglades National Park,

210 U.S. Geological Service-Biological Resources Division, U.S. Army Corps of Engineers

211 and the South Florida Water Management District. Reliable models from such research

212 are available that determine the impacts of water management on nesting patterns. Pattern

213 metrics (e.g. nest numbers and nesting success) are statistically correlated to Ecosystem

214 Drivers, and a Spatially Explicit Species Index model is being developed as part of the

215 Across Trophic Level System Simulation modeling effort. This research has provided

216 numerous peer reviewed journal articles. This indicator is already part of the CERP

217 RECOVER interim goals and Food-Web Monitoring Component of the CERP MAP.

\subsubsection{The indicator is sensitive to system drivers (stressors).}

221 Key environment drivers, such as water depth, hydroperiod and salinity, are

222 statistically correlated to spoonbill nesting success (Lorenz, 2000, Lorenz et al., 2002). A

223 causal link exists between hydropatterns, prey abundance and availability, and nesting

224 success (Lorenz, 2000, Lorenz and Serafy, 2006). Nesting failure has been statistically

225 linked to nest number and location in a given region such that persistent nesting failure

226 results in a decline in nesting effort and a concurrent increase in other regions.

228 1.4.4. The indicator is integrative. 
230 Spoonbill nesting success is linked to fish production and in turn, fish production 231 is linked to periphyton and SAV production. Spoonbill nesting responses are 232 representative of hydrological improvement (i.e. Water Management). Spoonbills are 233 also included in the CERP Food-Web Monitoring Component that includes an index 234 of food-web function and landscape connectivity ("intactness").

\section{2. The Spoonbill Indicator Performance Measures}

\subsection{Indicator Metrics}

The spoonbill indictor consists of four performance measures:

241 - Nesting success (average number of chicks fledged per nesting attempt and 242 number of years out of the last ten in which production exceeded 1.0 chicks per nest fledged)

244 - Number of nests

245 - Distribution of nests (number of nests in northeastern Florida Bay and 10,000 $246 \quad$ islands area)

247 - Prey community structure (percent of total community that are considered 248 freshwater species as defined by Lorenz and Serafy, 2006) 
In addition there will be a metric for spoonbills nesting in the northwestern region

251 of Florida Bay to act as a control metric for restoration efforts that will affect the

252 northeastern region.

254 2.2. The Stoplight Restoration Report Card System Applied to Spoonbills

This communication tool is based on MAP performance measures (either by

257 module or system-wide) and is expected to be able to distinguish between responses to

258 restoration and natural patterns. A set of parameters (Table 1) has been developed for

259 each performance measure. Answers are translated as suitability indices identified as

260 stoplight colors with green indicating that targets have been met, yellow indicating that

261 conditions are below the target but within a suitable range of it and red indicating the

262 measure is performing poorly in relation to the target. Two questions are addressed using

263 suitability indices: 1) have we reached the restoration target, or if not, 2) are we making

264 progress toward targets?

265

266 Methods for producing suitability curves vary among performance measures. For

267 example, a ten-year running average was used for percentage of years that spoonbills

268 were successful. A five-year running average was used for average annual nest

269 production and nest numbers. Fish community structure changes to a greater percentage

270 of freshwater species only when salinity conditions have been favorable to these species

271 for a two to three year period, therefore this parameter will be reported as an annual

272 metric that covers a three year period. Nesting success will be reported annually because 
273 short-term water depth conditions dominate this parameter. By using this suite of

274 performance measures this indicator covers time scales from annual to three, five and ten 275 year cycles.

281 five regions based on the primary foraging grounds for each of the colonies within each

282 region (Figure 2). They also demonstrated that, under the SDCS operations, the nest

283 productivity and nest number in the northeastern region have experienced a significant

284 decline. The method used to calculate this metric is based on surveys of focal colonies

285 (defined as the two largest colonies within the region). These surveys entailed marking

286 up to 50 nests shortly after full clutches had been laid and re-visiting the nests on an

287 approximate 7-10d cycle to monitor chick development. The metric is the number of

288 chicks per nest to survive to twenty-one days. After twenty-one days, the chicks become

289 very active and move throughout the colony precluding accurate accounting of individual

290 nest production. Since 2003, chicks have also been leg-banded so that individual chicks

291 can be identified. By resighting these individuals later in the nesting cycle, we are able to

292 use a second method to estimate nest production. Preliminary analysis of this mark-

293 resighting technique generally confirms that the twenty-one day survival is an accurate

294 method to calculate nest production.. 
297 nesting years out of ten with success being defined as an average nest production of

298 greater than one chick per nest (c/n) for all nest starts. This metric uses only the

299 northeastern region of the Bay (Figure 2) as this has been demonstrated to be the region

300 most impacted by water management practices (Lorenz et al., 2002). Prior to the

301 establishment of the SDCS, spoonbills nesting in the northeastern region averaged $71 \%$

302 successful years (Lorenz et al., 2002). Stoplight colors were based on this threshold

303 (Table 1, Figure 4).

304

305 The second metric of nest production is the five year mean of nest production in

306 the northeastern region. Lorenz et al., (2002) demonstrated that prior to the SDCS annual

307 mean spoonbill production in the northeast region was $1.38 \mathrm{c} / \mathrm{n}$ and that this dropped to

3080.67 post-SDCS. Initially we set this as the target for the stoplight metric where annual

309 production was divided by $1.5 \mathrm{c} / \mathrm{n}$ with greater than $67 \%$ set as the threshold for a green

310 rating. However, as can be seen in Figure 5, there are no trends in the data with rapid

311 changes occurring from one year to the next. This is due to the interannual differences in

312 hydrologic conditions that affect the ability of spoonbills to capture enough prey to

313 successfully raise young. Simply put, some years are naturally better than others. Taking

314 a multi-year running average smoothes this high variability into more interpretable trends

315 (Figure 5). By examining various time frames from previous data we concluded that by

316 using a five year running average, no single good or bad year out of the five skewed the

317 results into the red or green classification. A single good or bad year in either the two, 
318 three or four year running averages could bias the mean, thus resulting in an inaccurate

319 stoplight color.

321 There are natural background conditions that can result in nest failure that are

322 unrelated to CERP or water management practices. Therefore, we need to control for

323 natural background variation in foraging conditions. We dealt with this problem by using

324 the northwestern region's success rate as control for natural background conditions.

325 While the northeastern region's production declined post SDCS, the northwestern regions

326 production remained relatively high $(1.24 \mathrm{c} / \mathrm{n})$ even though there was still a great deal of

327 interannual variability. Lorenz and Frezza (2007) concluded that the interannual variation

328 in productivity of the northwestern colonies reflects the natural variation while the

329 variation in the northeast is affected by both this background and by water management

330 practices. Therefore, we propose that the metric used to gage success in the northeastern

331 region be tied to that of the northwestern, i.e., the metric should be calculated by dividing

332 annual northeastern production by that of the northwest thereby resulting in a percentage

333 (Figure 6). The thresholds for stoplight colors are presented in Table 1.

335 Although this metric solves the problem of natural interannual variation in nesting 336 success, it is also dependant on the continued high rates of success of the northwestern

337 colony. What happens if CERP or other issues begin to negatively affect the success of

338 the northwestern colonies? This would result in the metric receiving higher scores even

339 though there was actually a degradation of the bay for spoonbills. Therefore, stoplight

340 metrics were developed to examine the northwestern regions (explained below in section 
341 2.3.5). If all three of the metrics are yellow or red then the metric for northeastern

342 success should be based on the long term mean production rate of $1.5 \mathrm{c} / \mathrm{n}$ for northeastern

343 Florida Bay (Lorenz et al., 2002, Figure 5).

2.3.2. Number of spoonbill nests in Florida Bay. Spoonbill nest counts for

346 Florida Bay have been performed intermittently since 1935 (Powell et al., 1989). Over

347 that period, spoonbills have been recorded nesting on thirty-eight keys throughout the

348 Bay (Figure 2; Lorenz et al., 2002). Spoonbills typically establish nests in Florida Bay in

349 November or December of each year, however, nest initiation has started as early as

350 October and as late as March (Powell et al., 1989, Alvear-Rodriguez, 2001). All known

351 nesting keys are visited every twenty-one days during the nesting season. Our data show

352 that prior to the establishment of the SDCS, the peak number of nests was 1258 in 1978

353 (Figure 1, Lorenz et al., 2002). For this stoplight, annual nest counts are divided by 1258

354 to get the annual percentage of the historic peak number of nests (Figure 7) and assigned

355 the stoplight color as per Table 1.

356

357 2.3.3 Spoonbill nesting location. This stoplight indicator consists of two metrics:

358 a return to pre-SDCS nest numbers in the northeastern region and return of spoonbills to

359 nesting colonies along the southwest coast of the Everglades in the Shark River Slough

360 and Lostman's Slough estuaries. Powell et al., (1989) reported that in the peak year of

3611978 more than half of the 1258 nests were located in the northeast region (688 nests).

362 Following the completion of the SDCS, this number dropped to approximately 100 nests

363 from 2000 to 2007 . In 2008 there were a total of 47 nests in the region. For restoration 
364 to be considered successful, we should expect a return to nesting numbers to pre-SDCS

365 numbers. This metric is the percentage of 650 nests that occur annually (Figure 8).

366 Similar to nest success and total nests for Florida Bay, the interannual variation can bias

367 individual years and a five year mean was used for this metric (Table 1).

According to Scott (1889), spoonbills "nested in the thousands" along the

370 southwest coast of the Everglades in the Shark River and Lostman's slough estuaries.

371 Restoration of more historic hydrological conditions should promote greater prey

372 abundance and availability in this region, potentially leading to a return of spoonbill

373 nesting in large numbers. In recent years, Everglades National Park has performed aerial

374 wading bird surveys of this area and has documented spoonbill nesting (Pers. Comm,

375 Sonny Bass, Supervisory Wildlife Biologist, Everglades National Park), however

376 accurate surveys of spoonbills nest number can not be performed from aircraft because

377 they tend to nest low in the canopy. Although it is imperative to get a baseline for pre-

378 CERP nesting in this critical region, no funds have been identified to pay for this effort.

379 As a result, no stoplight metrics can be established at the time of this publication.

2.3.4 Prey Community Structure. Spoonbills primarily feed on small demersal

382 fishes found throughout the Everglades system (Allen, 1942, Dumas, 2000). Lorenz et

383 al., (1997) developed a methodology that uniquely sampled fishes in the dwarf mangrove

384 foraging grounds that are the preferred feeding locations for spoonbills nesting in Florida

385 Bay. The sampling design uses a $9 \mathrm{~m}^{2}$ drop trap at fixed locations at known spoonbill 
386 feeding sites. Data collection began in 1990 at four sites. Currently, there are 14

387 sampling sites associated with Florida Bay's nesting spoonbill population (Figure 2)

389 Lorenz (1999) documented that these fish respond markedly to changes in water

390 level and salinity and these factors can be altered by water management practices.

391 Lorenz and Serafy (2006) performed a fish community analysis of eight years of these

392 data from six sites. During the eight-year span reported by this study, there were three

393 consecutive years of unusually high rainfall and freshwater flows to the estuary which

394 resulted in low salinity similar those believed to have occurred in the region prior to

395 water management influences. As part of their analysis, Lorenz and Serafy (2006),

396 placed individual species in one of four salinity categories (freshwater, oligohaline,

397 mesohaline or polyhaline) based on the Venice System of Estuarine Classification

398 (Bulger et al., 1993). To accomplish this, the authors used the mean salinity for the thirty

399 days prior to a given collection (based on the findings of Lorenz, 1999) to identify the

400 range of salinities in which each species was found. The median score of each species

401 salinity range was then used to classify the species into one of the four categories.

402 During the period of low salinity and high fish abundance, Lorenz and Serafy (2006)

403 found that more than $40 \%$ of the total fish community were freshwater affiliates (Figure

404 3). Furthermore, they demonstrated that it took two to three years of low salinity for the

405 freshwater populations to respond. Finally, they demonstrated these low salinity

406 communities were much more productive based on both number and biomass of the

407 standing stock (Figure 3). The stoplight for prey abundance will use the percentage of

408 the fish community that was classified by Lorenz and Serafy (2006) as freshwater species 
410 integrative for the previous two years as well, i.e., this stoplight measures conditions on a

411 three year time scale.

\subsubsection{Monitoring nesting success in northwestern Florida Bay as a control. As}

414 stated above, comparing nesting success in the northeastern bay to that of the

415 northwestern bay accounts for background fluctuations on an interannual basis. For this

416 metric to work, however, there needs to be a control for any anthropogenically induced

417 reduction in nesting and productivity in the northwestern bay. We propose three stoplight

418 metrics to act as a control for the proposed comparison of the two regions. Lorenz et al.,

419 (2002) indicated that the mean production rate for spoonbill nests in the northeastern

420 region was $1.24 \mathrm{c} / \mathrm{n}$. Based on this we expect the five year mean production rate to

421 remain above $1.25 \mathrm{c} / \mathrm{n}$ and the control stoplight will remain green so long as this criterion

422 is met (Figure 9, Table 1). Since the completion of the SDCS, the northwestern region of

423 Florida Bay has produced a mean of 218 nests annually. Based on this metric, we set the

424 control metric for nest number at 200 and use a five year running mean of the percentage

425 of 200 as the stoplight indicator (Figure 9, Table 1). Finally, spoonbills have averaged

426 success in more than six of every ten years in the northwest region. The percentage of

427 successful years (mean production of $>1.0 \mathrm{c} / \mathrm{n}$ ) will also be used as a control with any

428 metric above six of ten years receiving a green stoplight score (Figure 9, Table 1). If all

429 three of the control metrics are yellow and/or red, than the metric for the northeastern bay

430 should be re-evaluated based on the historic trends of the northeastern region (Figure 5).

\section{3. Longer-Term Science Needs}


434 responses to hydrologic management effectively, are relatively well understood. The

435 techniques used to survey spoonbills is relatively well worked out, however, there are

436 components of their basic biology that are unknown. For example, life expectancy and

437 age at maturity are not known. Furthermore, migratory patterns are not well understood

438 and need to be assessed to determine if spoonbills nest in multiple locations annually or if

439 the nesting population in Florida Bay is distinct from other nesting locations around the

440 state. Also, our knowledge of the dispersal of fledglings from the nesting colony is

441 extremely limited. A banding program is underway to determine movements within the

442 state, however, further funding for this effort has not been identified and the program will

443 be eliminated without identification of funds. Furthermore, a satellite tagging program

444 would provide a great deal of information on international movements (e.g. Cuba,

445 Yucatan). This would also allow definitive data on local foraging flights. Currently, we

446 use inferences (such as flight line counts) to track where birds are feeding.

448 Currently there are no efforts to survey wading bird nesting colonies in the

449 estuaries of the southwestern coast of the Everglades even though this has been

450 documented as an important nesting area prior to the plume hunting era. A return to

451 nesting in this area has been identified as an important indicator for the restoration of

452 flows through Shark River and Lostman's sloughs. Funding for such surveys may be

453 expensive as they will require the use of a helicopter for access, however, it is imperative

454 that such funds be identified so as to maximize the use of this versatile indicator species

455 in the larger restoration plan. 
457 Of the seventeen existing prey fish sampling sites, three critical sites in

458 northeastern Florida Bay are not funded through any restoration effort. Secure funding

459 for these sites needs to be identified to preserve the statistical integrity of this effort.

\section{4. Discussion and Conclusions}

\subsection{Effectiveness of spoonbills as an Indicator of Ecological Restoration}

464 Spoonbills provide information to assess restoration of the Everglades that are 465 unique from other wading bird indicators and require different methods of assessing their

466 population trends. Therefore, spoonbills were identified as a separate indicator from the

467 other wading bird species for two reasons. First, spoonbills nest cryptically within the 468 canopy of mangroves and are not conspicuous from the air requiring nesting surveys to

469 be performed on the ground rather than aerially. As a result, different parameters have

470 been used to monitor spoonbills. Since we have to enter the nesting colonies to monitor

471 nesting effort, we are able to get more accurate counts of total nests, what region of

472 Florida Bay the nests were located, and the success of individual nests is documented 473 through mark and revisitation of the nests.

475 In southern Florida, spoonbills show a distinct fidelity to estuarine habitats with 476 approximately $90 \%$ of all nests found within Florida Bay, Tampa Bay and Indian River

477 Lagoon (although in recent years spoonbills have begun nesting at such inland freshwater 478 habitats such as the Corkscrew Swamp, Water Conservations Areas and mainland 
479 Everglades National Park). In contrast, other wading birds are much more plastic in there

480 selection of breeding sites with a well documented switch from coastal mangrove habitats

481 to the Water Conservation Areas in response to water management practices. Given

482 these differences, spoonbills are an indicator for Florida Bay, the southwest coastal

483 estuaries and, perhaps Biscayne Bay while other wading birds are indicators for central

484 Everglades habitats.

The RECOVER Conceptual Ecological Models identify three major stressors to

487 wetlands that are affecting the spoonbill nesting activities in Florida Bay: reduced 488 freshwater flow volume and duration (affecting hydrology and salinity, fish abundance 489 and availability); invasive exotic species (affecting primary producers and the prey base 490 fish community); and sea level rise (affecting habitat loss, wetland function and 491 geomorphology, preliminary and secondary production in the prey base) (Davis et al., 492 2005; CERP Monitoring and Assessment Plan; U. S. Army Corps of Engineers, 2004). 493 Only the first of these stressors will be ameliorated by CERP and, therefore, the spoonbill 494 assessment tool only addresses issues for water flow, volume and duration.

496 Changes in salinity patterns reduces primary production (through stresses caused 497 by rapid and frequent fluctuations in salinity; Montague and Ley, 1993, Ross et al., 2000, 498 Frezza and Lorenz, 2003) and alter the prey base fish community to a state of lower 499 secondary production (Lorenz, 1999, Lorenz and Serafy, 2006). As a result, the overall 500 abundance of spoonbill prey items is reduced. The spoonbill assessment tool includes a 
501 parameter that examines fish community structure which has been shown to have a direct

502 link to prey fish productivity thereby addressing this issue.

503

504 Changes in the timing and distribution of fresh-water deliveries, result in 505 increased water levels on the primary foraging grounds of spoonbills nesting in

506 northeastern Florida Bay (Lorenz, 2000). Studies performed in the mangrove foraging

507 grounds indicate that the prey base fishes begin concentrating into deeper creeks and

508 pools when water level on the wetlands drops to a certain depth threshold (Lorenz, 2000).

509 Spoonbills time nesting with falling water levels on these wetlands such that prey will be

510 concentrated at the time of egg hatching (Bjork and Powell, 1994). This provides a

511 highly available and consistent prey resource at a time when the energetic demands of

512 their rapidly growing young are highest. Out-of-season pulse releases resulting from

513 upstream water management activities rapidly raise water levels above the concentration

514 threshold and fish disperse across the surface of the wetland. This eliminates the needed

515 abundant and easily captured food resources for the spoonbills. Even brief reversal

516 events (3-5 days) can result in total failure of the spoonbill colonies. CERP and related

517 projects will alleviate this situation leading to higher nesting success and a return to

518 higher nest numbers in northeastern Florida Bay. The spoonbill metrics of nesting

519 success, location and number assess these components of the impacts of water 520 management practices.

521

522 The performance measure metrics chosen for spoonbills reflect current and

523 historic ecosystem conditions. The metrics used to evaluate spoonbills have been well 
524 documented in the literature and are based on the best understanding of how the Florida

525 Bay estuary functioned historically, currently and how we expect it to function under

526 restored conditions. The metrics used provide both spatial and temporal metrics to assess

527 the state of recovery efforts. We conclude that the spoonbill assessment tool will provide

528 a powerful and integrative means to evaluate CERP activities.

\subsection{Communicating the Spoonbill Indicator}

Roseate spoonbills, being a species that Everglades visitors seek out and

533 appreciate provide a valuable social as well as natural indicator. They are also well

534 accepted by managers and policy makers as a species that is important to our

535 understanding of estuarine systems. This is an important feature for system-wide

536 integrative indicators and we can capitalize on these points with the spoonbill indicator.

Making environmental decisions requires both effective communication of

539 environmental information to decision makers and consideration of what members of the

540 public value about ecosystems (Schiller et al., 2001). As described above, spoonbills are

541 good indicators (well-established relationships with environmental parameters under

542 management control) and the metrics (nest number and location, nesting success, prey

543 species composition) are remarkably easy to understand and communicate. The first

544 MAP Annual Assessment Report for spoonbills and their prey summarizes the most

545 recent advancements for spoonbills (System Status Report, 2006). The concepts of low

546 nest numbers, nesting in less desirable habitats, declines in nest success and prey 
547 abundance are all real concepts, with meaning to managers. Tracking improving or

548 declining conditions due to restoration activities with these metrics is easily

549 communicated and understood.

550

$551 \quad$ Literature Cited

552

553 Allen, R. P., 1942. The Roseate Spoonbill. Dover Publications Inc., New York.

555 Alvear-Rodriguez, E.A., 2001. The use of nesting initiation dates of Roseate Spoonbills 556 in northeastern Florida Bay as an ecosystem indicator for water management 557 practices. MS Thesis, Florida Atlantic University, Boca Raton, Florida.

559 Bartell, S.M., Lorenz, J.J., Nuttle, W.K., 2004. Ecological models for ENP evaluation of 560 CERP activities; Roseate Spoonbill Habitat Suitability Index model. Report to South Florida Research Center, Everglades National Park, Homestead FL.

563 Bjork, R. D. and Powell, G.V.N., 1994. Relationships between hydrologic conditions 564 and quality and quantity of foraging habitat for Roseate Spoonbills and other 565 wading birds in the C-111 basin. Final report to the South Florida Research 566 Center, Everglades National Park, Homestead, Florida. 
568 Bulger A.J., Hayden, B.P.,. Monaco, M.E., Nelson, D.M. McCormick-Ray, M.G., 1993.

569 Biologically based estuarine salinity zones derived from multivariate analysis.

$570 \quad$ Estuaries 16, 311-322.

571

572 Davis, S.M., Childers, D., Lorenz, J.J., Hopkins, T.E., 2005. A conceptual model of 573 ecological interactions in the mangrove estuaries of the Florida Everglades.

$574 \quad$ Wetlands 25, 832-842.

575

576 DeAngelis, D. L., Loftus, W.F., Texler, J.C., Ulanowicz, R.E., 1997. Modeling fish 577 dynamics and effects of stress in a hydrologically pulsed ecosystem. J. Aqua. $578 \quad$ Ecosys. Stress Rec. 6: 1-13.

580 Doren, R.F. 2006. Indicators for Restoration: South Florida Ecosystem Restoration. Report to the South Florida Ecosystem Restoration Task Force.

Dumas, J., 2000. Roseate Spoonbill (Ajaia ajaja). In: A. Poole and F. Gill (Eds.) The birds of North America. The Academy of Natural Science, Philadelphia.

586 Frederick, P., Spalding, M.G., 1994. Factors affecting reproductive success of wading 587 birds (Ciconiiformes) in the Everglades ecosystem. In: S. M. Davis and J. C. 588 Ogden, (Eds.) Everglades. The Ecosystem and Its Restoration. St. Lucie Press, 589 Boca Raton. 
591 Frezza, P.E., Lorenz, J.J., 2003. Distribution and abundance patterns of submerged 592 aquatic vegetation in response to changing salinity in the mangrove ecotone of 593 northeastern Florida Bay. Florida Bay Program and Abstracts form the Joint

594 Conference on the Science and Restoration of the Greater Everglades and Florida 595 Bay Ecosystem. University of Florida, Gainesville FL.

597 Gawlik, D. E., 2002. The effects of prey availability on the numerical response of wading $598 \quad$ birds. Ecol. Monogr. 72, 329-346

600 Kahl, M.P., 1964. Food ecology of the wood stork (Mycteria amaricana). Ecol. Monogr. $601 \quad 34,97-117$.

602

603 Light, S.S., Dineen, J.W., 1994. Water control in the Everglades: a historical perspective.

$604 \quad$ In Davis S.M. \& J.C. Ogden (Eds), Everglades: the Ecosystem and Its 605 Restoration, St. Lucie press, Delray Beach, FL.

606

607 Loftus, W. F., Kushlan, J.A., 1987. Freshwater fishes of southern Florida. Bull. Fla. $608 \quad$ State Mus. Biol. Sci. 31, 137-344.

609

610 Lorenz, J.J., 1999. The response of fishes to physicochemical changes in the mangroves 611 of northeast Florida Bay. Estuaries 22, 500-517. 
613 Lorenz, J.J., 2000. Impacts of water management on Roseate Spoonbills and their piscine 614 prey in the coastal wetlands of Florida Bay. Ph.D. Dissertation, University of Miami, Coral Gables FL.

617 Lorenz, J.J., Serafy J.E., 2006. Subtropical wetland fish assemblages and changing 618 Salinity regimes: implications of Everglades Restoration. Hydrobiologia 569, $401-422$.

621 Lorenz, J.J., Ogden, J.C., Bjork, R.D., Powell, G.V.N., 2002. Nesting patterns of Roseate Spoonbills in Florida Bay 1935 -1999: implications of landscape scale anthropogenic impacts. In: Porter, J.W. \& K. G. Porter (Eds), The Everglades,

627 Lovett, G.M., Burns, D.A., Driscoll, C.T., Jenkins, J.C., Mitchell, M.J., Rustad, L., 628 Shanley, J.B.,Likens, G.E., Haeuber, R., 2007. Who needs environmental monitoring? Front. Ecol. Environ. 5(5), 253-260.

631 McIvor, C.C., J.A. Ley \& R.D. Bjork, 1994. Changes in freshwater inflow from the 632 Everglades to Florida Bay including effects on the biota and biotic processes: a review. In Davis S.M. \& J.C. Ogden (eds), Everglades: the Ecosystem and Its Restoration, St. Lucie Press, Delray Beach, FL: 117-146. 
636 Montague, C.L., Ley, J.A., 1993. A possible effect of salinity fluctuation on abundance 637 of benthic vegetation and associated fauna in northeastern Florida Bay. Estuaries $638 \quad 16,703-717$.

640 Powell, G. V. N., Bjork, R.D., Ogden, J.C., Paul, R.T., Powell, A.H., Robertson, W.B., 641 1989. Population trends in some Florida Bay wading birds. Wils. Bull. 101, 436642 457

644 Ross, M. S., Meeder, J.F., Sah, J.P., Ruiz, P.L., Telesnicki, G., 2000. The Southeast 645 Saline Everglades revisited: a half-century of coastal vegetation change. J. Veg.

647

648 Scott W.E.D., 1889. A summary of observations on the birds of the gulf coast of Florida. Auk 6, 13-18.

650

651 Schiller, A., Hunsaker, C.t., Kane, M.A., Wolfe, A.K., Dale, V.H., Suter, G.W., Russell, 652 C.S., Pion, G., Jensen, M.H., Konar, V.C., 2001. Communicating Ecological

654

655 U. S. Army Corps of Engineers. 1999. CERP Central and Southern Florida 656 Comprehensive Review Study. Final Integrated Feasibility Report and 657 Indicators to Decision Makers and the Public. Cons. Ecol. 5(1), 19. Programmatic Environmental Impact Statement. Jacksonville District, United States Army Corps of Engineers, Jacksonville, FL. 
660 U. S. Army Corps of Engineers. 2004. CERP Comprehensive Monitoring and Assessment Plan http://www.evergladesplan.org/pm/recover/recover_map_2004.cfm

663

664 Williams, B.K., Szaro, R.C., Shapiro, C.D., 2007. Adaptive Management: The U.S.

665 Department of the Interior technical guide. Adaptive Management Working

666 Group, U.S. Department of the Interior, Washington, DC.

Acknowledgements

671 We would like to thank Greg May, the Executive Director of the South Florida

672 Ecosystem Restoration Task Force, and Rock Salt, Co-chair of the Science Coordination

673 Group, for their support in making the publication of the special issue of Ecological

674 Indicators possible. We would also like to thank G. Ronnie Best, U.S. Geological

675 Survey, for additional financial support in the publication of this special issue. This

676 description of crocodilians as an ecological indicator for restoration of Greater

677 Everglades ecosystems borrowed both inspiration and words directly from the template

678 for Fish and Macroinvertebrates prepared by Joel Trexler and Bob Doren. 
679 Table 1. Decision rule targets and scores for forming performance measure/suitability

680 relationships for the Roseate Spoonbill indicator communication tool.

681

682 1. Northeastern Nesting Success: number of successful nesting attempts (average of $>1$ chick

683 fledged per nest attempt) out of the previous 10 years in northeastern Florida Bay. Target is 7

684 out of 10 successful years based on the pre-SDCS average (Lorenz et al., 2002)

685 a. $0-3 \quad$ Red

686 b. $3-6 \quad$ Yellow

$687 \quad$ c. $7-10 \quad$ Green

688

6892 Northeastern Nest Production:

690 A. Five year mean of northeastern Florida Bay nest production expressed as a percentage of 691 northwestern Florida Bay nest production. This metric will be used if any of the control

692 metrics for northwestern Florida Bay (number 7 below) are green. In the case of none of the 693 controls being scored green than 2B will be used.

$694 \quad$ a. $\quad 0-33 \quad$ Red

695 b. $33-66 \quad$ Yellow

696 c. $>66 \quad$ Green

697

698 B. Five year mean of the percentage of mean pre-SDCS nest production. Target is 1.5 chicks

699 per nest attempt is based on the mean nest production from 1962 to 1982 (Lorenz et al.,

700 2002). This metric will only be used when all of the northwestern Florida Bay control

701 metrics (number 7 below) are scored as yellow and/or red. In the case of any of the controls

702 being scored a green than $2 \mathrm{~A}$ will be used.

703 a. $0-50 \quad$ Red 
$704 \quad$ b $50-100 \quad$ Yellow

$705 \quad$ c. $>100 \quad$ Green

706

707 3. Nest Number: five year mean of the percentage of pre-SDCS peak nest numbers found

708 throughout Florida Bay. Target is 1250 based on the peak number of nests found in 1978

709 (Powell et al., 1989).

$710 \quad$ a. $\quad 0-50 \quad$ Red

711 b. $50-100 \quad$ Yellow

$712 \quad$ c. $>100 \quad$ Green

713

714 4. Florida Bay Spoonbill Nesting Location: five year mean of the percentage of pre-SDCS peak

715 nest numbers found in northeastern Florida Bay. Target number is 625 based on the peak

716 number of nests found in 1978 (Powell et al., 1989).

$717 \quad$ a. $\quad 0-33 \quad$ Red

$718 \quad$ b. $33-66 \quad$ Yellow

719 c. $>66 \quad$ Green

720

721 5. Nesting in Southwestern Everglades Estuaries: No targets or stoplight scores can be set at this 722 time 
724 6. Prey Community Structure: Annual percentage of prey base fish sampling that are classified as 725 freshwater species according to Lorenz and Serafy (2007). Target is that $40 \%$ of the total 726 annual catch collected at six sampling sites within the foraging grounds of spoonbills nesting

727 in northeastern Florida Bay (Figure 2: TR, EC, WJ, JB, SB, and HC) are freshwater species

728 using data. Note that this metric is integrative of three years.

$729 \quad$ a. $0-20 \quad$ Red

$730 \quad$ b. $20-40 \quad$ Yellow

$731 \quad$ c. $>40 \quad$ Green

732

733 7. Northwestern Florida Bay Control Metrics:

734 A: Five year mean of the percentage of mean post-SDCS nest production in northwestern

735 Florida Bay. Target is 1.24 chicks per nest attempt is based on the mean nest production

736 from 1982-2002 (Lorenz et al., 2002).

$737 \quad$ a. $\quad 0-50 \quad$ Red

$738 \quad$ b $50-100 \quad$ Yellow

$739 \quad$ c. $>100 \quad$ Green

741 B. Five year mean of the percentage of post-SDCS mean nest numbers found in northwestern 742 Florida Bay. Target number is 200 based on the number of nests from 1982-2002 (Lorenz et 743 al., 2002).

744 a. $0-50 \quad$ Red

745 b $50-100 \quad$ Yellow

746 c. $>100 \quad$ Green 
748 C. Number of successful nesting attempts (average of $>1$ chick fledged per nest attempt) out of 749 the previous 10 years in northwestern Florida Bay. Target is 6 out of 10 successful years

750 based on the post-SDCS average (Lorenz et al., 2002)

$751 \quad$ a. $0-2 \quad$ Red

752 b. $3-5 \quad$ Yellow

$753 \quad$ c. $6-10 \quad$ Green

754

755 8. Cumulative Spoonbill Stoplight Metric: the mean of the 6 (or 7 if nesting location on the 756 southwest coast of Florida can be calculated from future efforts) non-baseline

757 stoplights where red is scored 1, yellow is scored 0.5 and red is zero.

$758 \quad$ a. $\quad 0-33 \quad$ Red

759 b. $33-66 \quad$ Yellow

760 c. $>66 \quad$ Green

761 


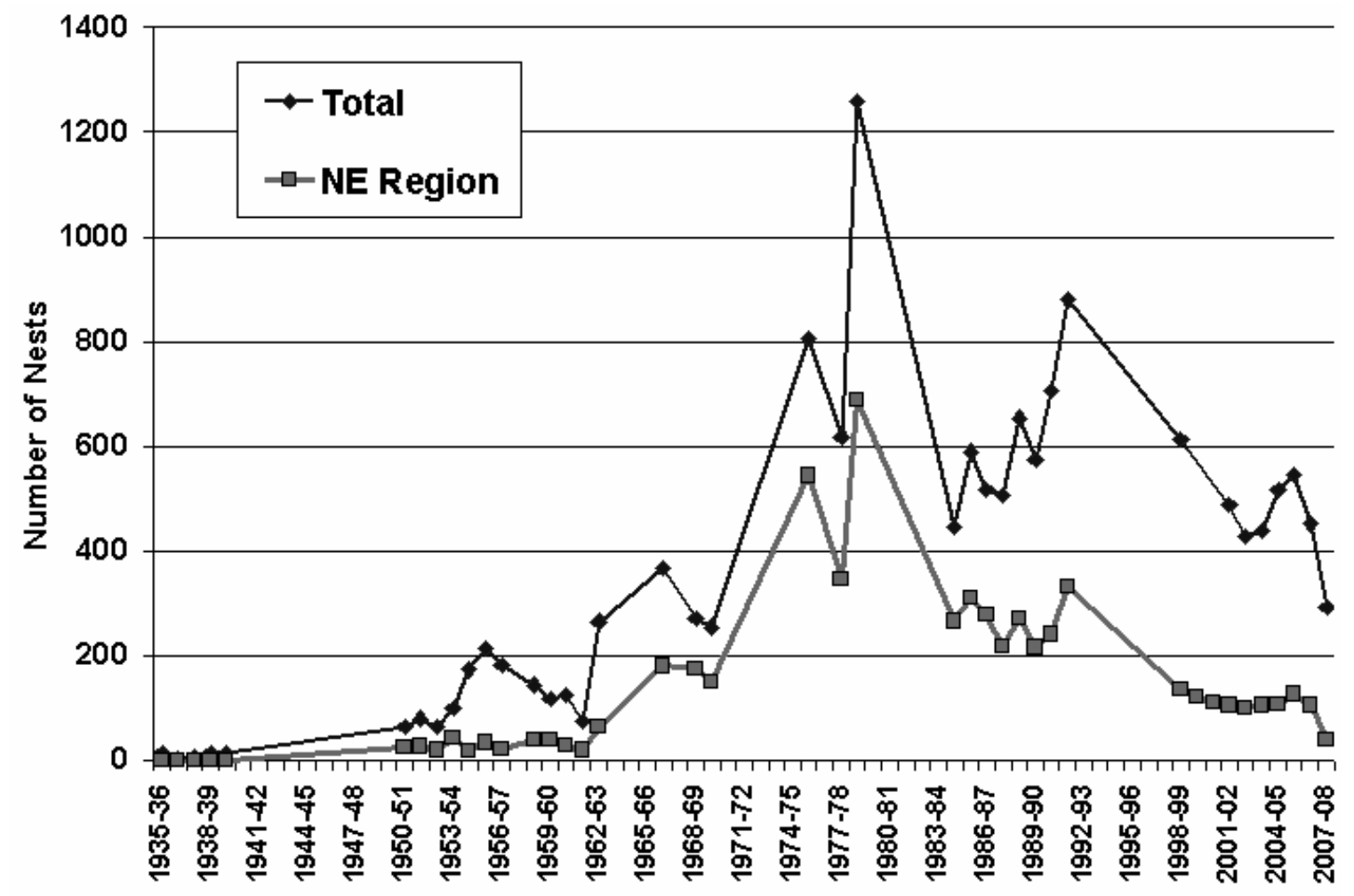

Figure 1. Annual number of roseate spoonbill nests for all of Florida Bay (Total) and for just the northeastern region of the bay from 1935 to 2008 . 

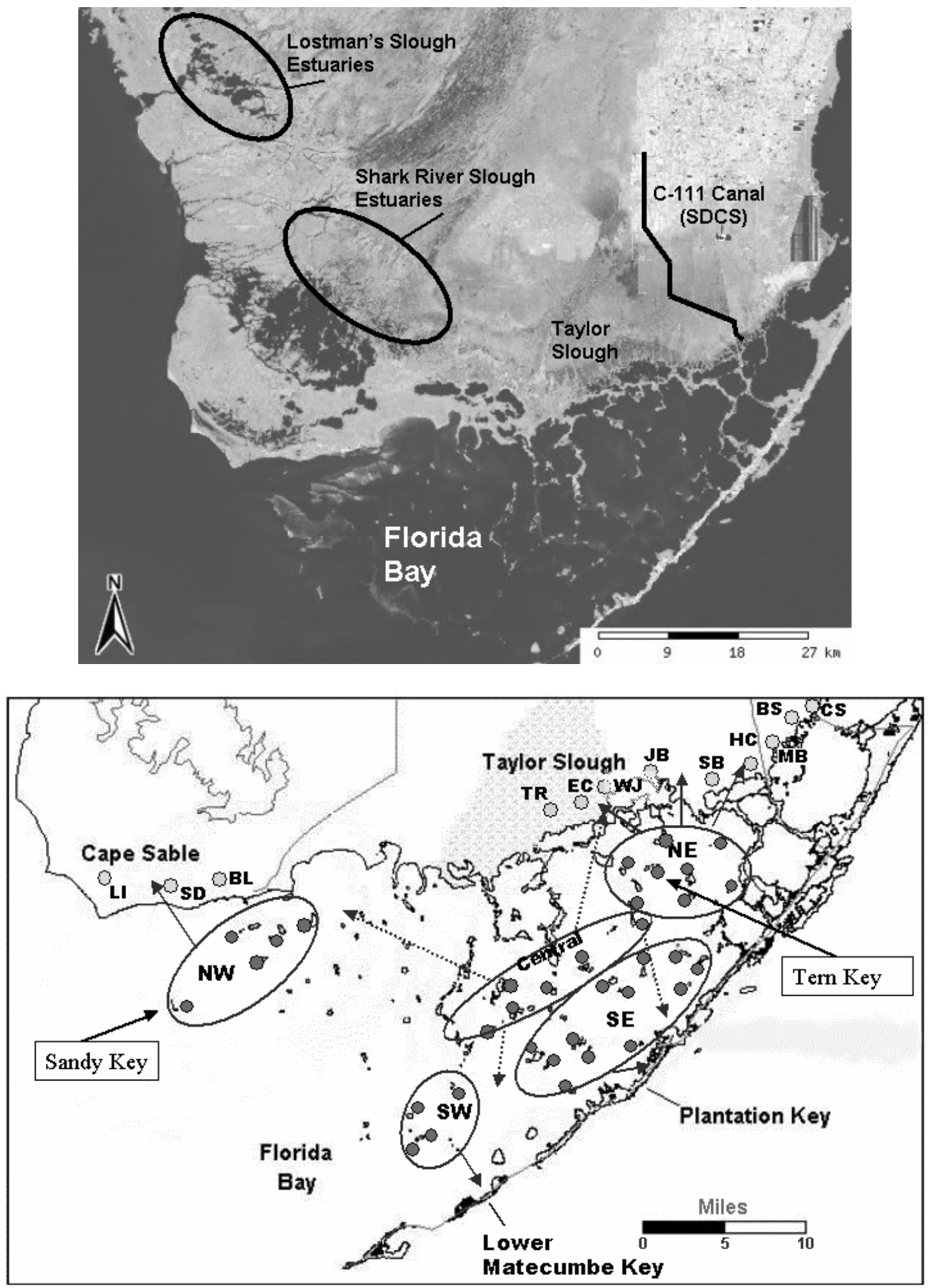

Figure 2. Top : Map of southern Florida indicating the major features discussed.

Bottom: Map of Florida Bay indicating all the nesting locations for spoonbills since 1935, the primary foraging areas for five regions of Florida Bay and the fish sampling sites used to evaluate the spoonbill's forage base. 

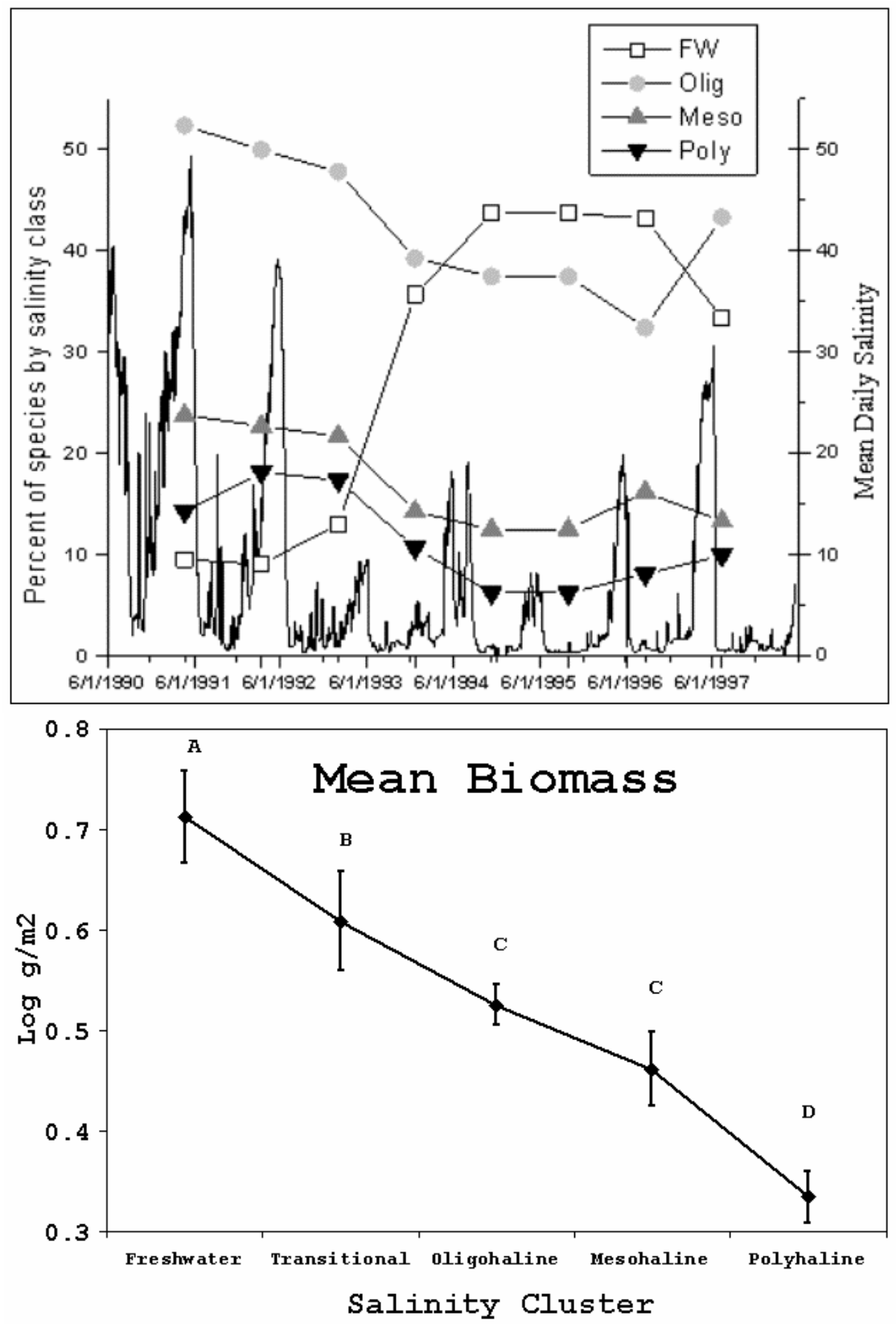

Figure 3. Top: Left Axis : Percent of total species collected annually at the three estuarine fish sampling sites (Figure : TR, JB, HC) by each salinity category as defined by Lorenz and Serafy 2006. Right Axis: Mean daily salinity from the three sites for the period of record. Note that years following a high salinity dry season have lower representation of freshwater species and higher representation of mesohaline and polyhaline species. The figure also indicates that it takes 2 to 3 consecutive years of low salinity for the freshwater species to become the dominate fish category. (Copyright: Hydrobiologia). Bottom: Differences in fish biomass between salinity categories as defined by Lorenz and Serafy (2006) using Non-Metric Multidimensional Scaling from eight years of fish collections at 6 sites. Their results show that samples dominated by lower salinity species have significantly higher biomass than those dominated by higher salinity species. (Copyright: Hydrobiologia). 


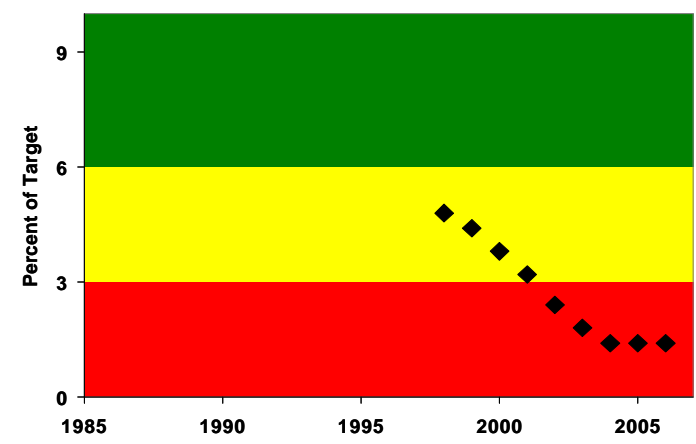

Figure 4. Decadal metric for percent of years nesting was successful. The percentage years out of the previous ten in which spoonbills nesting in northeastern Florida Bay were successful ( $>1$ chick per nest fledged). These data demonstrate the declining number of successful years in spoonbill nesting since 1998 . Note that due to data limitations we used the five year average in the figure, however, the ten year mean will be used for the actual stoplight metric.
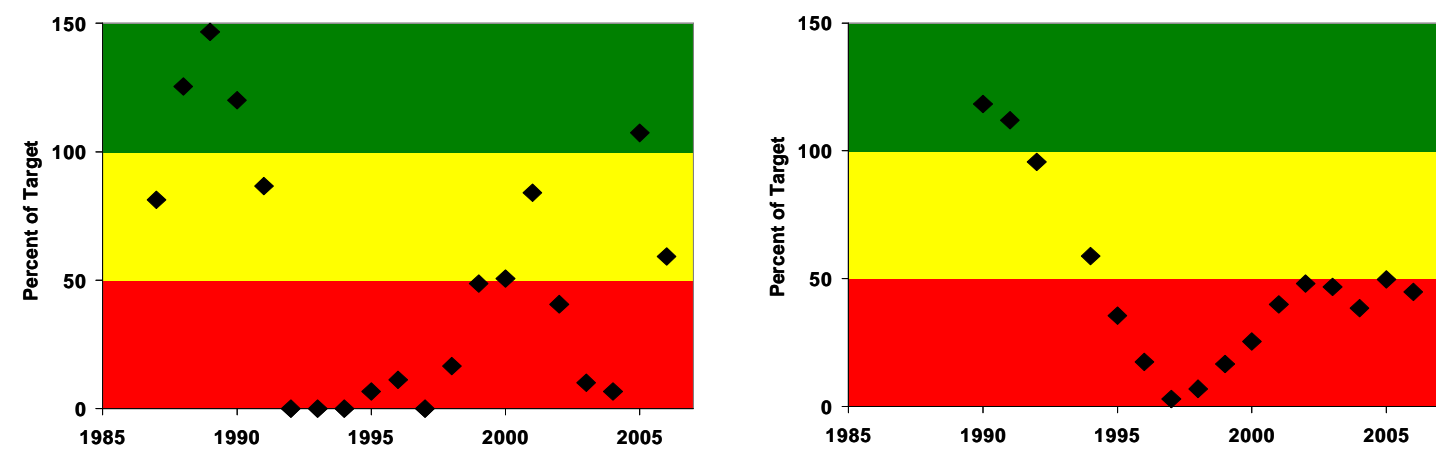

Figure 5. Five year metric used for nest production in northeastern Florida Bay. Left: Percentage of the target production rate of 1.5 chicks per nest fledged in northeastern Florida Bay since the completion of the South Dade Conveyance System (SDCS). The target is based on pre-SDCS nest production data presented by Lorenz et al (2002). Right: The five year running mean of data presented in the figure on the left. Note that due to data limitations the first 3 data points are four year averages, however, the five year mean will be used for the actual stoplight metric. This metric will only be used if the three control metrics for northwestern Florida Bay (Figure ) are scored yellow and/or red.
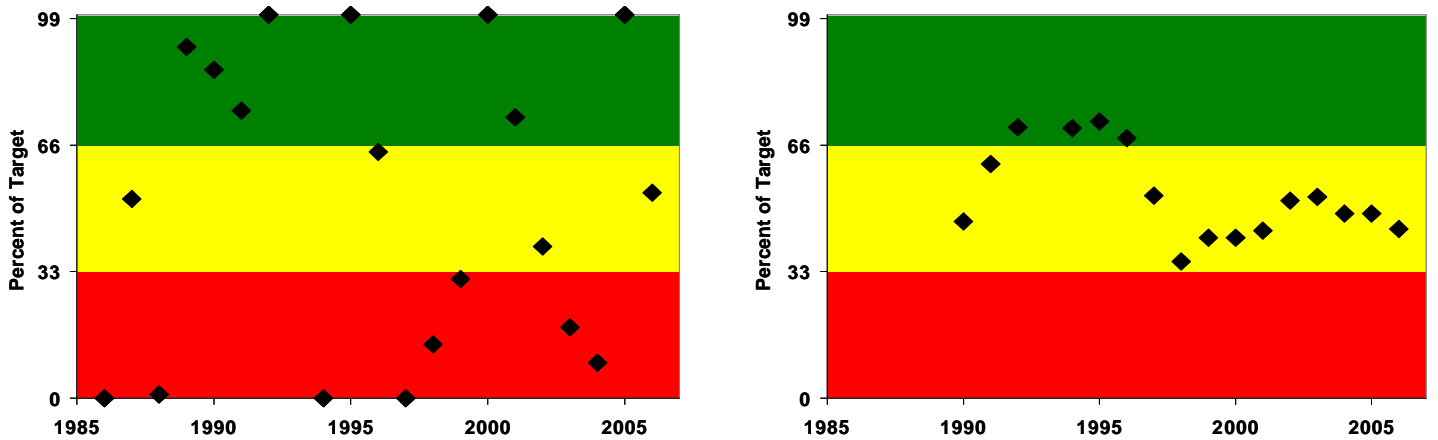

Figure 6. Five year metric used for nest production in northeastern Florida Bay. Left: Northeastern Florida Bay nest production (in chicks fledged per nest attempt) as a percentage of northwestern Florida Bay production since the completion of the South Dade Conveyance System. Right: The five year running mean of data presented in the figure on the right. This metric will be used as the stoplight metric for nest productivity unless the three control metrics for northwestern Florida Bay (Figure ) are scored yellow and/or red 

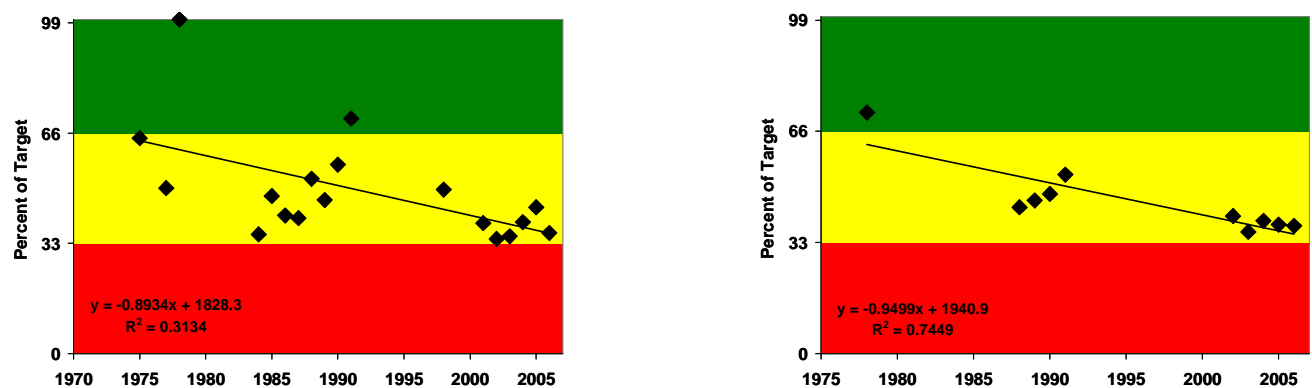

Figure 7. Bay wide nest number metric. Left: Number of nests bay-wide as a percentage of a target of 1250 nests. The target was set based on the maximum number of nests in Florida Bay prior to the completion of the South Dade Conveyance System (SDCS) as reported by Powell et al (1989). . Right: Five year running mean of the data presented to the right. Note that due to data limitations the earliest data point was a mean of only 3 years, however, the five year mean will be used for the actual stoplight metric.
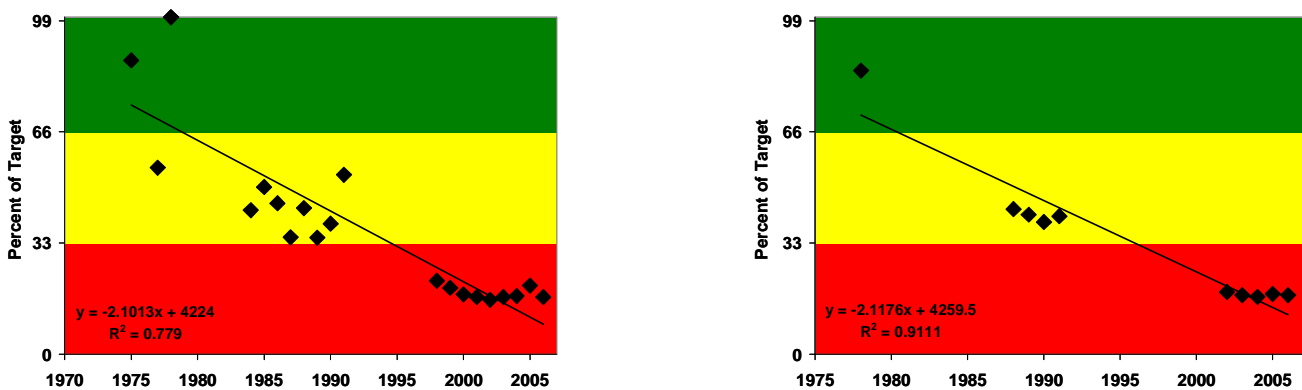

Figure 8. Nest location metric for northeastern Florida Bay. Left: Number of nests in northeastern Florida Bay as a percentage of a target of 625 nests. The target was set based on the maximum number of nests in northeastern Florida Bay prior to the completion of the SDCS as reported by Powell et al (1989). Right: Five year running mean of the data presented to the right. Note that due to data limitations the earliest data point was a mean of only 3 years, however, the five year mean will be used for the actual stoplight metric.
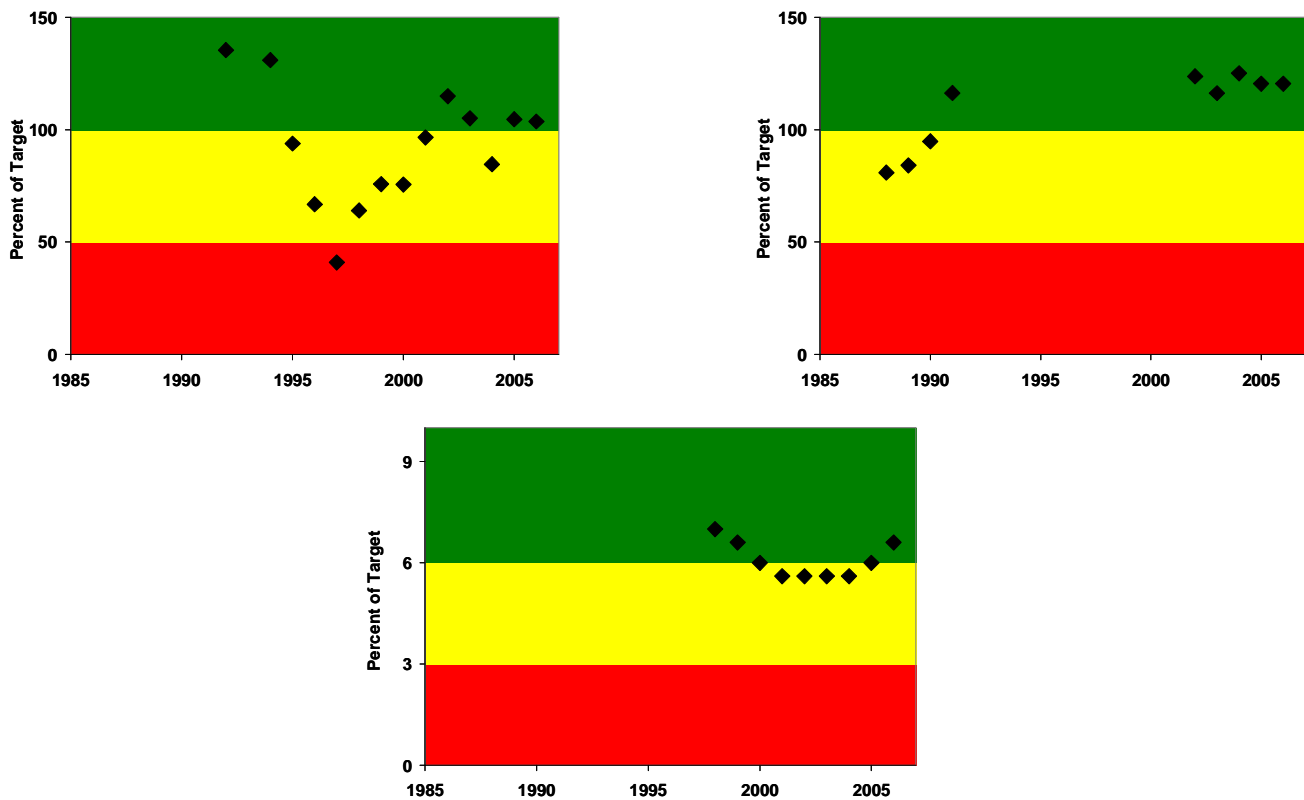

Figure 9 Control metric for using northwestern Florida Bay production as the standard for calculating the stoplight metric in northeastern Florida Bay (Figure ${ }^{\wedge}$ ). Top Right: Percentage of the target production rate of 1.25 chicks per nest fledged in northwestern Florida Bay since the completion of the SDCS. The target is based on the post-SDCS nest production data presented by Lorenz et al (2002). Top Left: Five year mean of the number of nests in northwestern Florida Bay as a percentage of a target of 200 nests. The target was set based on the average number of nests in northwestern Florida Bay since the completion of the SDCS as reported by Lorenz et al (2002). Bottom: The percentage years out of the previous ten in which spoonbills nesting in northeastern Florida Bay were successful ( $>1$ chick per nest fledged). Note that due to data limitations we used the five year average in the figure, however, the ten year mean will be used for the actual stoplight metric. 